\title{
WHAT THIS BOOK AIMS TO DO
}

As soon as you are faced with a new wordprocessing program it can take a bit of adjustment and concentration to find your way around it. The trouble is, you never have any time to go on a training course or sit down and read the manual. The Macmillan Modern Office series has been designed to take the headache out of learning. There is great value in learning something the right way from the beginning. Everyone knows that unless you have a driving instructor you will develop bad habits and often make life difficult for yourself. What's more you will probably fail your driving test!

If you put a few minutes aside each day and aim to complete just one lesson in this book you will minimise mistakes and produce work with efficiency and speed.

Each lesson concentrates on one simple exercise. Usually you will study one main feature and practise it fully. Each lesson begins with a short list of the features that will be covered or revised and ends with a brief summary of what you will have learned. Experienced users will find the summary invaluable.

The first time that you study a command, such as underlining text, for example, a step-by-step guide will be used. As you gain proficiency the amount of detail will be reduced.

By the time you reach the end of this Basic Course you will have achieved total competence in all the most important features of MultiMate Advantage II. Study the Advanced Course too if you need to use the spelling checker, libraries, macros, merge, columns, calculations, create a mini-database, alter the defaults or create tables of contents - to name but a few of the many features available.

Each time that you are asked to press something or key-in some text, the instructions will appear in the column marked Action. The effect of this action will then be displayed in the column marked Result.

Typing is minimal. However, you cannot expect to get away without typing anything at all. It has been proved that you will usually only remember a feature if you do it yourself. Practice really does make perfect.

This book will help you to teach yourself MultiMate Advantage II. You can go at your own speed and repeat any lessons that trouble you. It is worth noting that Lessons One and Two are far more detailed than later lessons. This is because someone completely new to the concept of word. processing needs a lot of help and tuition in the early stages. If you are using this book to cross-train yourself be patient with Lesson One, later exercises will be completed more quickly.

Use this book as a training course. The author has been a wordprocessing trainer for a number of years and uses examples of proven worth. If you can find the time to study the whole book in one day then it will have been a day well spent. 